\title{
Fryns Syndrome
}

National Cancer Institute

\section{Source}

National Cancer Institute. Fryns Syndrome. NCI Thesaurus. Code C98932.

A rare syndrome inherited in an autosomal recessive pattern. It is characterized by the presence of diaphrag matic defects, distinctive facial features (hypertelorism, low-set ears, flat nasal bridge, and micrognathia), distal digital hypoplasia, lung hypoplasia, and brain, gastrointestinal, and cardiovascular malformations. 